$\underline{\text { Review Article }}$

\title{
SYSTEMATIC REVIEW ON MEDICAMENTS USED IN MANAGEMENT OF DIABETES MELLITUS
}

\author{
ANUPAM JAMWAL \\ Government Pharmacy College Kangra, Nagrota Bagwan, District Kangra, 176047 Himachal Pradesh, India \\ Email: anupam_pharma84@yahoo.co.in
}

Received: 16 May 2020, Revised and Accepted: 18 Jun 2020

\begin{abstract}
Diabetes has a global prevalence in developed countries and rapidly flexing its roots in middle-and low-income countries. According to the World Health Organization, it is a major cause of kidney collapse, heart problems, and lower limb amputation. Diabetes mellitus is a metabolic disorder showing an uncontrolled increase in blood glucose levels. To date, no permanent cure has been developed for the complete restoration of impaired glucose haemostasis. With the use of therapeutic agents and nontherapeutic agents, glucose levels can be kept in control for a very long time. The foremost goal of all current ongoing treatments is to control high blood glucose levels, reduction in elevated lipid levels, and delay in the progression of diabetes-related complications. Various therapeutics agents are developed in recent decades, which shown very promising results in the management of diabetes mellitus. These agents prescribed after reviewing the clinical symptoms and situation of an individual patient. This review compiles noteworthy information related to clinically approved medicaments for diabetes mellitus. Review emphasis on categorization,
\end{abstract} mechanism of action, noted adverse effects along with the physiological responses of used medicines to treat diabetes mellitus.

Keywords: Diabetes mellitus, Hypoglycaemic drugs, Insulin, Antidiabetic drugs, Type 1 diabetes mellitus, Type 2 diabetes mellitus

(C) 2020 The Authors. Published by Innovare Academic Sciences Pvt Ltd. This is an open access article under the CC BY license (http://creativecommons.org/licenses/by/4.0/) DOI: http://dx.doi.org/10.22159/ijpps.2020v12i8.38345. Journal homepage: https://innovareacademics.in/journals/index.php/ijpps.

\section{INTRODUCTION}

\section{Management of diabetes mellitus}

The aim of therapy in the treatment of diabetes is to control elevated levels of glucose levels, symptoms related to hyperglycemia, and chronic complications. Management of diabetes has been broadly classified into three domains viz., glycemic control, treat associated conditions, and diabetic complications [1]. Diabetes mellitus is a chronic condition with higher levels of glucose in the body. This alteration in glucose homeostasis is due to the dysfunction of insulin hormone, which helps in mobilization of glucose into cells and produce energy. Diabetes mellitus is further classified into two types i.e. type 1 diabetes mellitus (T1DM) and type 2 diabetes mellitus (T1DM) [2]. The glycated haemoglobin $\left(\mathrm{HbA}_{1 \mathrm{c}}\right)$ is considered to be the most precise and best standard for judgment of patient diabetes records in recent years because it provides a sign of a 2 to 3 -month glycaemia record [3]. Formulated insulin is obtained from different species of animals with little variation from human insulin e. $g$ porcine and beef insulin has been used in the treatment of severe diabetic conditions [4]. Porcine insulin at the C-terminal amino acid of chain $\mathrm{B}$ has alanine and human insulin contain threonine. Beef insulin differs with three different substitutions viz., alanine (B30), valine (A10), and alanine (A8) $[5,6]$. These isolated forms of insulin were used when DNA recombinant technology is not available. They are usually avoided due to adverse immunological responses like type I allergy and injection-site lipoatrophy $[7,8]$. American diabetes association has laid down four criteria for the diagnosis of diabetes.

1. Fasting glucose level $\geq 126 \mathrm{mg} / \mathrm{dl}$ (impaired glucose tolerance) and non-fasting plasma glucose $\geq 200 \mathrm{mg} / \mathrm{dl}$

2. Oral glucose tolerance test (OGTT) $\geq 200 \mathrm{mg} / \mathrm{dl}$

3. Hyperglycaemic symptoms (Polyphagia, polyuria, polydipsia)

4. Glycated haemoglobin $\left(\mathrm{HbA}_{1 \mathrm{c}}\right) \geq 6.5 \%$

The Management of diabetes mellitus is followed by insulin therapy, oral hypoglycaemic drugs, other chemical agents, and nontherapeutic methods [9]. The present review includes particulars of currently used allopathic medicaments in the treatment of diabetes mellitus worldwide. The main objective to compile the present review systematically to learn and narrate with classifications, mechanisms of actions, efficacy, and common side effects of FDA approved drugs used in antidiabetic therapies as monotherapy, addon therapy, or in combinations. This review also prominence on physiological reactions like effects on insulin resistance and insulin sensitivity, weight gain or loss, developmental risk, or decline in risk for diabetic complications produce by antidiabetic drugs. It also vaguely covers the effects of hypoglycaemic drugs on metabolic activities and elevated biochemical levels, which are commonly reported in diabetes mellitus patients. The major databases like Google Scholar, MEDLINE, Scopus-Elsevier, Directory of Open Access Journal (DOAJ), and Open J-Gate are employed to compile the current review in January 2020. The important keywords such as antidiabetic drugs, hypoglycaemic drugs, T1DM and T2DM drugs, oral hypoglycaemic medicaments, types of insulin, and mechanism of action of antidiabetic drugs are brought into play for literature compilation.

\section{Insulin therapy}

Insulin therapy is the main course of treatment for T1DM and uncontrolled hyperglycaemia T2DM [1]. The various insulin delivery systems are available for the administration of insulin e. g., portable pen injectors, inhaled insulin, insulin degludec, insulin syringes, and infusion pumps. Insulin is also administered intravenously, intramuscular, and traditionally insulin is administered by a subcutaneous route [10]. Insulin therapy is given to control abrupt glucose changes in the diabetic state. Thus, insulin administered must be similar in pharmacokinetic profile as that of endogenous insulin released from the pancreas, i.e., a rapid rise in blood concentration, short duration of action and rapid clearance [11] Commercial available insulin preparations are different from human insulin in the amino acid sequences, solubility, and onset/duration of action. Four types of injectable insulin preparations are available with the different onset of actions and prepared with recombinant DNA technology viz., rapid-acting, short-acting, intermediate-acting, and long-acting [12]. Nearly, all the long-acting insulin reduces the levels of glycated haemoglobin $\left(\mathrm{HbA}_{1 \mathrm{c}}\right)$ levels to normal limits [13]. Type 1 diabetic patients are treated with insulin therapy after confirmation of disease symptoms. Patients counseling is necessary before prescribing insulin therapy, e. g., amount of food intake in terms of carbohydrate, need for physical activity, and hypoglycaemia effects [14]. Two types of insulin therapy regimens are followed in 
the management of diabetes i.e. intensive and conventional therapy. Intensive insulin therapy is also known as flexible insulin therapy, in which current glucose levels and amount of carbohydrate intake in the meal is considered before the administration of human regular insulin [15]. Hypoglycaemia is the most common reported side effect in intensive insulin therapy [16]. In conventional insulin therapy, premixed human insulin (30\% regular and $70 \% \mathrm{NPH})$ is administered before breakfast and dinner, which is followed by fixed diet plans [17]. The intensive insulin therapy consisted of daily three or more insulin injections and conventional insulin therapy is designed to control glucose levels with one or two insulin injections daily [18]. Intensive insulin therapy delays diabetic complications related to T1DM, e. g., nephropathy, neuropathy, retinopathy, and microvascular complications when compared with conventional insulin therapy [19]. Diabetic patients, along with complications like coronary artery surgery, acute stroke, stress, and acute myocardial infarction, have a $20 \%$ higher risk of death. Intensive insulin therapy in diabetic and non-diabetic patients with critical illnesses or the surgical intensive care unit reduces morbidity and mortality [20]. In the case of childhood diabetes especially in T1DM, intensive insulin therapy is found to be safer [21]. T2DM patients which undergo gastrectomy for cancer treatment, intensive insulin therapy, reduces short term morbidity [22]. In acute neurological injury, intensive insulin therapy shows better control of glucose levels and reduces morbidity [23]. The therapy causes severe hypoglycemia if regular monitoring of plasma glucose levels is not recorded. Thus, new automated techniques like islet transplantation, insulin delivery, and preservation of endogenous insulin have been developed in recent years [24].

\section{Rapid-acting insulin}

A rapid-acting insulin is the safe, very fast onset of action, rapid clearance, and effective for a short duration. Commercially, three injectable forms are available viz., insulin lispro, insulin aspart, and insulin glulisine. A rapid-acting analog does not cause hypoglycaemia or nocturnal hypoglycaemia and shows better control of postprandial glucose [25]. These insulin analogs can be administered before or immediately after meals [26]. Insulin lispro is first marketed insulin preparation in the USA. Insulin lispro has alternation in the amino chain-B of insulin, i.e., proline (B-29) and lysine (B-28). This alteration increases the dissolution rate of insulin because the dimeric form of insulin is converted into monomer and rapidly absorbed, but this modification does not change receptor binding affinity [27]. Insulin aspart is another commercially available rapid-acting insulin preparation for human use and made by the substitution of proline (B-28) with aspartic acid. This exchange alters the interaction between monomer-monomer, i.e., aspartic acid (B-28) and glycine (B-23), which cause a decrease in insulin self-aggregation [12, 28]. Insulin glulisine causes quick disposal of postprandial glucose after post-meal and physiological action similar to regular human insulin [29]. It is produced by substitution of lysine in place of asparagine at B-3 and glutamic acid at B-29 replacing lysine [12]. Insulin glulisine in the solution form exists as a monomer without zinc and has rapid absorption. Thus, it is less immunogenic when compared with other rapid-acting insulin but may cause rare insulin autoimmune syndrome [30]. It is proving to be the most effective and safe insulin preparation for children suffering from T1DM [31].

\section{Short-acting insulin}

Short-acting insulin analogs did not show any hazard of severe hypoglycaemia and shown better management of $\mathrm{HbA1c}$, postprandial glucose, and diabetic ketoacidosis [32]. Regular insulin is short-acting insulin made by DNA recombinant technology. It exists as a hexamer form, which is bulky and creates depot upon subcutaneous injection and result delay in transportation through blood [1]. The onset of action of regular insulin is appearing within $30 \mathrm{~min}$ and the duration of action is about 2 to $3 \mathrm{~h} \mathrm{[12].}$

\section{Intermediate-acting insulin}

Intermediate-acting insulin has delay onset of action and absorption. Three types of intermediate-acting insulin have been used clinically viz., NPH (Neutral Protamine Hagedorn or isophane), insulin glargine, and insulin detemir. $\mathrm{NPH}$ at neutral $\mathrm{pH}$ is a combined product of insulin and stoichiometric protamine in the isophane ratio, i.e., neither insulin nor protamine found in large concentrations [33]. NPH is poorly soluble insulin product in blood and due to this property, it results in delayed onset of action (onset of action is 2-5 $\mathrm{h}$ and duration of action is 4-5 h). NPH insulin shows little improvement in HbA1clevel when compared with other intermediate-acting insulins [12]. Insulin glargine, intermediateacting insulin, is having two modifications, i.e., the addition of two arginine molecules at C-terminus of B-chain of human insulin and replacement of asparagine by glycine. This addition of arginine causes a slight increase in the solubility of insulin glargine towards acidic $\mathrm{pH}$ and a shift in isoelectric point from $\mathrm{pH} 5.4$ to 6.7 [34] Insulin glargine has shown a greater affinity towards insulin-like growth factor-1 receptors compared to regular insulin [35]. The onset of action of insulin glargine is slow, with significant activity maintained for 11-24 h [36]. It can be administrated any time during a day and significantly reduces HbA1c levels and prevent hypoglycemic shocks during nights [37]. Insulin detemir is a new long-lasting analog that is created by the substitution of myristic acid at B-29 position and removal of threonine from the B-30 position [38]. These modifications cause self-aggregation and protein binding with albumin. The duration of action of insulin detemir is more than $12 \mathrm{~h}$ and having 1-2 $\mathrm{h}$ onset of action [36]. Insulin detemir is considered to be much safer than NPH [12]. It shows better control on glycaemia in T1DM because it does not precipitate after subcutaneous administration, binds to albumin protein in the blood, and forms depot, which can be buffered easily if a change occurs in absorption parameters [39].

\section{Mixtures of insulin}

A mixture of insulin is a formulation created by mixing rapid and short-acting insulin in the same syringe before administration such as insulin lispro, aspart, glulisine with NPH. Other mixtures of insulin are NPL (Neutral protamine Lispro) and NPA (Neutral Protamine Aspart) [12]. Insulin preparation containing $50 \%$ of short-acting insulins are termed as high-mix insulins. These mixtures are well-tolerated, provide efficient control over glycaemia and can be administered once or twice daily [40]. The premixed formulation, like $70 \% \mathrm{NPH}$ and $30 \%$ regular insulin, improves efficacy, accuracy and gives better control over glycaemia [41].

\section{Oral antidiabetic agents}

The oral antidiabetic drugs are used for the treatment of T2DM, which is not controlled with diet restriction and physical exercise. Six categories of oral antidiabetic agents have been available in the market viz., biguanides, sulfonylureas, meglitinides, thiazolidinediones, alpha-glucosidase inhibitors, dipeptidyl peptidase-IV (DPP-4) inhibitors, sodium-glucose cotransporter-2 (SGLT2) inhibitors, other agents and non-therapeutic methods [12, 42]. The first-line therapy for T2DM treatment is started with the most widely used oral antidiabetic drug, i.e., metformin. The second line of therapy involves sulfonylureas, thiazolidinediones, glucagonlike polypeptide-1 (GLP-1) agonists, dipeptidyl peptidase-IV (DPP-4) inhibitors, meglitinides, and SGLT2 inhibitors [43].

\section{Biguanides}

Metformin, a dimethyl biguanide, is used in the treatment of T2DM chronically without an increase in the risk of hypoglycemia [44]. Its efficacy, tolerance, safety, improved peripheral insulin sensitivity without an increase in insulin secretion, weight gain, and other beneficial effects on cardiovascular systems promote this drug as best for the treatment of diabetes mellitus [45]. The prediabetic risk development in patients with impaired glucose tolerance in the Indian population has been significantly reduced with metformin [46]. American Diabetes Association and American Association of Clinical Endocrinologists recommend monotherapy with metformin for the earlier treatment of hyperglycaemia in adult T2DM patients [47]. Metformin is only biguanide currently in use, other derivatives like phenformin and buformin have been withdrawn from the market due to reported adverse effects like lactic acidosis and cardiac mortality in the early 1970s [48]. Metformin lowers blood glucose levels in both obese and non-obese T2DM patients and proves to be as effective as sulfonylurea derivatives [49]. Metformin 
clinically reduces $\mathrm{HbA}_{1 \mathrm{c}}$ level and can be used in combination with other oral antidiabetic drugs without gastrointestinal effects [50]. Other cellular mechanisms for metformin are via inactivation of gluconeogenesis enzymes production mediated through 5'AMP activated protein kinase (AMPK), increase glucose uptake in skeletal muscles, and adipocytes [51]. AMPK mediated mechanism of action of metformin has been challenged by genetic loss-of-function studies and suggested other AMPK-independent possible mechanisms that explain metabolic effects and side effects of metformin [52] Metformin also acts through peroxisome proliferator-activated receptor (PPAR)- $\alpha$, which induces islet incretin secretion and increases the glucagon-like peptide 1 (GLP-1) levels [53]. In skeleton muscles, metformin causes delocalization of GLUT1 protein but no effect on GLUT4 glucose transporters and stimulates glucose uptake [54]. Metformin has also been found to reduce cancer risk in T2DM [55]. Weight loss is associated with metformin in long term treatment. Hypoglycemia is usually not reported with metformin unless it is administered with sulfonylureas and insulin [56]. The gastrointestinal disturbances like anorexia, diarrhoea, metallic taste and gut discomfort are common side effects reported with metformin but can be resolved with dose modifications [57]

\section{Sulfonylureas}

Sulfonylureas are developed in the 1920s and used in the treatment of T2DM. The chronic use of sulfonylurea normalizes insulin levels to baseline with reduced glucose levels. Sulfonylurea is a hormonereleasing agent [58]. Sulfonylurea acts as insulin secretagogues and stimulates insulin release from $\beta$-cells of the pancreas [59]. Sulfonylureas are classified into two group's viz., first and secondgeneration agents. The less potent agents are including in firstgeneration agents, e. g., Acetohexamide, Chlorpromazine, Tolazamide, and Tolbutamide. The potent sulfonylureas are included in secondgeneration agents e. g., Glibenclamide, Glimepiride, Gliclazide, and Glipizide are available in the markets for the treatment of T2DM [60] They inhibit ATP-sensitive K-channels in $\beta$-cell and initiate a cascade of events that result in the release of insulin from granules. ATPsensitive K-channels is a complex consisting of two subunit proteins Kir6.2 (pore-forming subunit) and SUR1 (drug-binding regulatory subunit) [61]. SUR1 is a receptor binding site for sulfonylurea, which initiates the closing of ATP- $\mathrm{K}^{+}$channels and decreases efflux of potassium, which causes depolarization of the plasma membrane of $\beta$ cell. Cellular influx triggers depolarization and is mediated through voltage-dependent $\mathrm{Ca}^{2+-}$ channels, and promotes the first and second phases of insulin secretion from preformed insulin granules [62] Gliclazide and tolbutamide selectively inhibit ATP-sensitive Kchannels in $\beta$-cell through SUR1 subunit, not SUR2 subunit in cardiac and smooth muscle. Other agents like glibenclamide, glimepiride repaglinide, and meglitinide inhibit both subunits of ATP-sensitive Kchannels [63]. Hypoglycaemia, an increase in body weight, and secondary failure are noted side effects of sulfonylureas [64]. The chronic use of sulfonylureas significantly increases the risk of coronary heart disease in women [65]

\section{Meglitinides}

Meglitinides are nonsulfonylurea insulin secretagogues and act as rapid-acting postprandial insulin releasers. They too increase insulin secretion similar to sulfonylurea. The two marketed meglitinides are repaglinide and nateglinide [66]. Meglitinides bind to Kir6.2 (poreforming subunit) of ATP-sensitive K-channels present on the plasma membrane of $\beta$ cells of the pancreas [67]. Meglitinides are not effective in patients with dysfunction $\beta$-cells in the pancreas [68]. The monotherapy with repaglinide proves to be more effective in reducing $\mathrm{HbA}_{1 \mathrm{c}}$ and fasting glucose levels in comparison to nateglinide [69]. Repaglinide shows better tolerance and appears to be a safe alternative in geriatrics diabetic patients [70]. They have a rapid and short duration of action due to short half-life and potentiate only firstphase insulin release. This contributes to a lower risk of hypoglycaemia. The adverse reactions of meglitinides are similar to sulfonylurea but with a mild decrease in body weight [71]

\section{Thiazolidinediones}

Thiazolidinediones or glitazones are a new class of oral antidiabetic agents and are FDA approved drugs for T2DM, e. g., pioglitazone and rosiglitazone. Thiazolidinediones enhance insulin action, increase glucose muscle uptake, and cause suppression of gluconeogenesis. They reduce the concentration of circulating free fatty acids, triglycerides, and cause a rise in the levels of HDL and LDL cholesterol [72]. Thiazolidinediones decrease insulin resistance by repression of hepatic glucose output and increasing insulindependent glucose metabolism, thus, used in the treatment of T2DM associated with insulin resistance [73]. Thiazolidinediones enhance insulin sensitivity and alter transcription of genes which modulate carbohydrate and lipid metabolism. They are ligands for peroxisome proliferative activated receptor-gamma (PPAR-gamma) in muscle, adipose tissue, and liver [71]. PPAR-gamma activation causes transcription in genes for lipoprotein enzyme lipase, adipocyte fatty acid-binding protein, fatty acyl-CoA synthase, glucokinase, and GLUT4. Thiazolidinediones diminish insulin resistance through the activation of endocrine signalling in skeletal muscle and liver [74]. Rosiglitazone and other PPAR gamma activator agents inhibit activation of the c-Jun $\mathrm{NH}_{2}$-terminal kinase (JNK) signaling pathway and enhance the survival rate of $\beta$-cells of the pancreas [75]. The reported side effect of thiazolidinediones is oedema when used in combination therapy with insulin. Thiazolidinediones also aggravate the risk of congestive heart failure in T2DM patients [76].

\section{Alpha-glucosidase inhibitors (AGIs)}

Alpha-glucosidase is a membrane-bound enzyme present in the small intestine and assists in the absorption of carbohydrates after a meal [77]. Alpha-glucosidase inhibitors (AGIs) have a similar mechanism of action, i.e., inhibition of carbohydrates absorption from the gastrointestinal tract. AGIs are pseudo-sugars that competitively and reversibly inhibit the $\alpha$-glucosidase enzyme and cause a delay in the absorption of carbohydrates from the gut [78]. These are used in the management of T2DM patients with impaired glucose tolerance [79]. Voglibose, Miglitol, and Acarbose are the most widely used AGIs for the treatment of T2DM and decrease postprandial plasma glucose and insulin levels [80]. AGIs are most beneficial for T2DM patients having higher postprandial plasma glucose levels and normal HbA1c. A clinical situation where glucose levels are not controlled with monotherapy of other oral antidiabetic agents, diet, and exercise, AGIs can be used as first-line of a drug in combination therapy [78]. Acarbose is used as add-on therapy in poorly controlled T2DM patients with diet sulfonylurea and biguanide. The starting dose of AGI is low and administered after meals. These inhibitors reduce glucose level about $54 \mathrm{mg} / \mathrm{dl}$ and HbA1c $0.9 \%$ [81]. The common side effects of AGIs are flatulence, gut discomfort, diarrhoea, and bloating. Hepatic injury is a rare side effect reported with AGIs use [82]

\section{Dipeptidyl peptidase 4 inhibitor or gliptins}

There are two primary incretin hormones secreted from the intestine after post-meal are glucagon-like peptide-1 (GLP-1) and gastric inhibitory polypeptide (GIP). Incretin hormones stimulate insulin secretion from $\beta$-cells of the pancreas and regulate glucose homeostasis [83]. In response to elevated glucose concentration after a meal, incretin hormones (GLP-1 and GIP) enhance insulin release from $\beta$ cells, and additionally GLP-1 decreases glucagon production [84]. In hypoglycaemia state, GIP promotes glucagon counter-regulation and increases $\alpha$-cells sensitivity for glucose [85]. Incretin hormones action is mediated through activation of adenylate cyclase and high level of cyclic adenosine monophosphate (cAMP) [86]. Incretin mimetics are a new class of drugs used in the treatment and management of T2DM, e. g., dipeptidyl peptidase 4 inhibitors (DPP-4 Inhibitor) and GLP-1 receptor agonist [87]. In plasma, dipeptidyl peptidase-4 (DDP-4) cause's cleavage of two $\mathrm{NH}_{2}$ terminal amino acids of both GIP and GLP-1, thus, block the action of incretin hormones which results in reducing insulin level and higher postprandial glucose [88]. DPP-4 Inhibitor effectively decreases HbA1c without causing an increase in the body weight [89]. Five DPP-4 inhibitors are available in market viz., sitagliptin, vildagliptin, saxagliptin, linagliptin, and alogliptin [90].

Sitagliptin is a selective and efficacious dipeptidyl peptidase 4 inhibitors used for the management of T2DM and well-tolerated with ongoing metformin therapy [91]. Recent studies reveal sitagliptin monotherapy reduces both fasting and non-fasting glucose level along with improved functioning of $\beta$ cells in T2DM 
[92]. Sitagliptin is also found to be valuable and safe in treatment T1DM. It exhibits better control over glycaemia when used in combination with insulin therapy. The proposed mechanism of action of sitagliptin in type 1 diabetes mellitus mediated through suppression of glucagon production [90]. Vildagliptin is a new oral hypoglycaemic drug and acts as a selective inhibitor of the dipeptidyl peptidase-4 enzyme [93]. Vildagliptin causes prolonged inhibition of the DPP-4 enzyme and diminishes GLP-1 degradation. It increases insulin secretion, decreases glucagon concentration, inhibits gluconeogenesis, and enhances insulin sensitivity [94] Vildagliptin increases insulin to glucagon ratio, which results in the enhancement of glucose sensitivity of $\alpha$-cell and $\beta$-cell of the pancreas in T2DM patients. Insulin to glucagon ratio decreases in the hypoglycaemic state, resulting in the stimulation of hepatic glucose production [95]. A recent study shows that vildagliptin monotherapy or in combination with other antidiabetic agents is safe and well-tolerated but requires add-on therapy [96]. Vildagliptin and metformin in combination therapy efficiently lower blood glucose levels as compared to glimepiride-metformin treatment with a lower incidence of hypoglycaemia and a slight increase in body weight [97]. Saxagliptin is a reversible inhibitor of the DPP-4 enzyme, which binds covalently on catalytic active serine hydroxyl site and reduces degradation of incretin hormone and promotes insulin secretion [98]. DPP-4 enzyme inhibitors are used for better tolerability in the early stage of diabetes mellitus [99]. It is approved by the FDA in July 2009 and recommended as an add-on to the non-therapeutic approach in T2DM, i.e., dietary modification and physical exercise [100]. Saxagliptin metabolite is less potent as a parent drug [101]. Saxagliptin is proved to be safe both in monotherapy and in combination. It is also effective in lowering glycosylated haemoglobin, fasting plasma glucose, and non-fasting glucose [102]. Saxagliptin is found to be inferior to vildagliptin but superior to sitagliptin in controlling glucose levels [103]. Saxagliptin regularizes retinal capillary flow and glucose homeostasis in T2DM [104]. Common side effects reported in saxagliptin monotherapy are diarrhoea, respiratory infection, mild hypoglycaemia, and headache [105]. Linagliptin, a xanthine base, is a selective inhibitor of the DPP 4 enzyme [106]. It decreases HbA1c levels in diabetes with a good tolerability profile in a patient with renal defects. It is well tolerated in obese, geriatric patients and does not require dose adjustment [107]. Linagliptin shows a better safety profile over sulfonylurea without causing an increase in body weight, stroke, and cardiovascular effects [108]. It enhances insulin sensitivity and reduces liver fat in hepatic steatosis [109]. Alogliptin is a highly selective noncovalent DPP-4 inhibitor and approved by the FDA in January 2013. It is prescribed for monotherapy or in combination with metformin and pioglitazone for T2DM [110]. Alogliptin is well tolerated and its monotherapy gives similar control over hyperglycaemia as other DPP-4 inhibitors without hypoglycaemia [111]. The combination therapy of alogliptin and pioglitazone improves $\beta$ cell function while monotherapy of alogliptin gives better control of glycaemia [112]. The recent study shows that alogliptin prevents the progression of non-alcoholic fatty liver disease in T2DM patients [113]. The common side effects reported with alogliptin are respiratory infection, body pain, and nasopharyngitis [114].

\section{Incretin mimetic or GLP-1 receptor agonist}

Incretin mimetic or GLP-1 receptor agonists, a new generation of drugs that increase insulin release, inhibit glucagon secretion, and reduce appetite [115]. Seven incretin mimetics are available in market viz., Exenatide, Liraglutide, Albiglutide, Dulaglutide, Semaglutide, Taspoglutide and Lixisenatide. Exenatide (exenatide immediate-release injection, exenatide extended-release injection) is GLP-1 receptor agonist and the first member of incretin mimetic. It is approved by the FDA in 2005 as add-on therapy with metformin and sulfonylurea for the management of T2DM [115]. Exendin-4 is 39 amino acid peptide hormone having biological properties similar to glucagon-like peptide-1 (GLP-1). Exenatide is a synthetic product of exendin-4. Exenatide controls glycaemia via glucagon secretion suppression, progressive stimulation of insulin secretion, increase in $\beta$ cell cellular mass, and enhancement of peripheral tissue glucose uptake [116]. The most common side effect reported with exenatide is nausea [117]. Liraglutide is a long-acting GIP-1 receptor agonist and having $97 \%$ resemblance to human incretin hormone, i.e., GLP-1 [118]. Liraglutide is an injectable GLP-1 analog approved by the FDA in February 2014 for the management of T2DM. Clinical studies show that liraglutide in add-on therapy with metformin and thiazolidinediones decreases the higher glucose level and welltolerated by T2DM patients [119]. Liraglutide significantly reduces fasting and non-fasting glucose levels with a lower incidence of hypoglycaemia [120]. The obese patients are at higher risk for the development of diabetes and cardiovascular disease. Such patients are advised for weight reduction. Liraglutide decreases insulin resistance, lowers blood pressure, and fatty acid concentration [121]. The obese patient with T1DM on insulin treatment, liraglutide is added for better control on glucose and glycated haemoglobin level. Liraglutide add-on therapy causes a reduction in insulin dose and body weight [122].

Albiglutide is a DPP-4 enzyme resistant long-acting GIP-1 receptor agonist and approved in many countries for the treatment of T2DM. It stimulates postprandial insulin release and delays gastric emptying resulting in reduced food intake [123]. Albiglutide administered once in a week through a subcutaneous route and exhibits less gastrointestinal side effects compared to other incretins mimetic. It is the choice of agent in diabetes with renal failure [124] Dulaglutide, a GLP-1 receptor agonist, administered once in a week, used as an adjunct to non-therapeutic methods and produced by recombinant DNA technology. Various clinical trial studies show dulaglutide monotherapy effectively control hyperglycaemia [125]. Dulaglutide efficiently reduce glycated haemoglobin with common side effect i.e. gastrointestinal discomfort [126]. Semaglutide is the latest approved GIP-1 receptor agonist for the treatment of T2DM by the US Food and Drug Administration and European Medicines Agency. It shows a significant decrease in glycated haemoglobin and systolic blood pressure along with the incidence of gastrointestinal side effects when administered orally once in a week [127] Taspoglutide, long-acting GIP-1 receptor agonists shows better control over increased glycaemia compared to exenatide and sitagliptin. It shows adverse events like reduction in body weight and allergic reactions, which lead to frequent discontinuation [128] Lixisenatide is a selective GLP-1 receptor agonist, used in the treatment of T2DM in adults. It is approved as add-on therapy to diet and exercise. Lixisenatide manage glycaemic record in monotherapy and in combination with other medicaments [129]. It acts via increasing glucose-induced insulin secretion with a rapid onset of action [130]. Lixisenatide does not produce symptomatic hypoglycaemia and associated cardiovascular risk [131]

\section{Sodium-glucose co-transporter-2 (SGLT2) inhibitors}

SGLT2 inhibitors offer a distinctive mechanism of action and consider the newer class of medicament in the treatment of Diabetes mellitus. SGLTs are active co-transporters that facilitate passive glucose transporters (GLUTs) for glucose reabsorption in the proximal convoluted tubule. To date, six SGLTs were identified but SGLT1 and SGLT2 are considered valuable in glucose haemostasis [132]. SGLTs inhibition causes glucose excretion in urine, which results drop in blood glucose levels without the involvement of insulin. SGLT2 inhibitors such as dapagliflozin, canagliflozin, ertugliflozin, and empagliflozin having a low risk of hypoglycaemia and well-tolerated as monotherapy or in combinations other antidiabetic medicaments [133]. Dapagliflozin, a highly selective SGLT2 inhibitor, reduces blood glucose levels, glycosylated haemoglobin, and body weight with low-risk hypoglycaemia [134] The common side effects of dapagliflozin in the clinical trial are female genital mycotic infections, urinary tract infections, and nasopharyngitis [135]. Canagliflozin is another SGLT2 inhibitor that effectively reduces plasma glucose levels with cardiovascular and renal benefits such as blood pressure and albuminuria [136]. It also reduces $\mathrm{HbA1c}$ in type 1 diabetic patients when used as an add-on to insulin therapy [137]. Ertugliflozin is a recent oral SGLT2 inhibitor that gets FDA approval as an antidiabetic drug. It prevents reabsorption of urine glucose and shows better control of body weight and blood pressure [138]. Ertugliflozin reduces cardiovascular risk due to a fair decline in blood pressure and body weight. Therefore, it is also recommended as an adjunct drug with non-therapeutic treatment methods like diet management and 
exercise in T2DM [139]. Empagliflozin is a selective SGLT2 inhibitor administered orally to decrease blood glucose levels via urinary glucose excretion. It is well tolerated and no dose adjustment is required in diabetic patients with renal or hepatic impairment [140] Empagliflozin in a clinical trial on T2DM patients with cardiovascular disease show marked reduction in cardiovascular risk but urosepsis or genital infection was sporadic reported [141]

\section{Other agents}

Amylinomimetic drugs are the synthetic analogue of amylin, a naturally occurring 37-amino-acid peptide hormone released from the pancreas, and helps in glucose homeostasis. T2DM patient possesses a low level of amylin while T1DM patient does not produce amylin from the pancreas [142]. Pramlintide, an approved amylinomimetic drugs by the US FDA for the treatment of T1DM along with insulin, and in the case of T2DM, it is used as an adjunct with insulin, metformin and sulfonylurea [143]. Pramlintide reduces postprandial blood glucose in both T1DM and T2DM patients with side effects like hypoglycaemia [144]. Bromocriptine mesylate, dopamine (D2) agonist approved by the FDA for the treatment of T2DM and used as both monotherapy and in combination with other oral hypoglycaemic agents. Bromocriptine reset the tone of dopaminergic and circadian neuronal activities in the hypothalamus and central nervous system [145]. The drug is well-tolerated, reduces glycated hemoglobin by $0.4-0.8 \%$, and reduce cardiovascular risk [146]

\section{Non-therapeutic methods}

In recent decades, the incidence of diabetes is constantly increasing and widely spread among Indian communities especially in males $[147,148]$. The higher prevalence of obesity and diabetes in the urban population is related to unhealthy lifestyles, i.e., lack of exercise, unhealthy dietary habits, and overeating [149, 150]. Diabetes mellitus even in early on stages cause a decline in skeletal muscle strength and loss of physical function [151]. Diet control and weight reduction have shown an advantageous effect on insulin action and sugar level in the mild T2DM. It is related in terms of change in macronutrients and abdominal fat [152]. In T1DM variation in dose regime of rapid and short-acting insulin has been made according to the carbohydrate content of meal to meal for better control on hyperglycaemia [153]. A similar approach has been recommended for T2DM. In obese T2DM patients, increase unsaturated fat consumption in meals causes a decrease in insulin sensitivity and an increase in body weight. Protein metabolism is altered in both types of diabetes mellitus. Type 1 diabetic patients tend to convert amino acids into glucose. Thus, modification in protein content has been recommended [154]. In T2DM, protein metabolism does not increase glucose levels instead protein ingestion causes stimulation of insulin release, C-peptide and glucagon [155]. Day to day lifestyle, lack of physical activities has increased developmental risk of T2DM in young, adult, and older people. Exercise or burning off extra calories found to be helpful in the prevention and control of T2DM and weight gain [156]. The eight-week-long exercise regime exhibit decrease in glycosylated haemoglobin irrespective to body weight. It is also reported that an increase in the intensity of physical exercise further results in the improvement in glycosylated haemoglobin [157]. Physical activities improve insulin sensitivity and decrease elevated glucose levels in the body. The risk of diabetes in a pre-diabetic patient with impaired glucose tolerance is reduced by a higher expenditure of energy and weight loss [158]. It also reduces the incidence of cardiovascular diseases associated with T2DM [159]. The patients counseling with informational booklet increase compliance for treatment and cause a decrease in glycaemic levels [160]

\section{CONCLUSION}

Diabetes mellitus, chronic condition with elevated glucose levels in the body. Its prevalence in the world increased rapidly, especially in urban and suburban areas. The insulin hormone maintains normal homeostasis in human beings. The management of insulin levels in terms of its concentrations and activities is the prime focus of current therapies. To achieve the afore-mentioned objective various medicaments i.e. insulin formulation and oral hypoglycaemic agents, were developed, which show a higher potency rate. A range of insulin preparation with the different onset of action was used to control glucose levels e. g., rapid-acting insulin, short-acting insulin, intermediate-acting insulin. Oral hypoglycaemic agents are used when insulin is present within the body but insulin sensitivity to a great extent reduced. These agents include metformin, sulfonylureas meglitinides, thiazolidinediones, DPP-4 inhibitors, GLP-1 receptor agonists, SGLT2 inhibitors. Metformin improves insulin response sulfonylureas normalize insulin levels in the body, meglitinides stimulate insulin release, thiazolidinediones enhance insulin sensitivity, and DPP-4 inhibitors reduce glucose level without causing an alteration in body weight, GLP-1 receptor agonists slower the rate of glucose absorption from the intestine and SGLT2 inhibitors halts glucose reabsorption in the kidney. The changes in lifestyle i.e. exercise and diet restrictions, also help in maintaining glucose levels in the body.

\section{FUNDING}

Nil

\section{AUTHORS CONTRIBUTIONS}

All the authors have contributed equally.

\section{CONFLICT OF INTERESTS}

There is no conflict of interest.

\section{REFERENCES}

1. Goodman LS, Gilman A. The pharmacological basis of therapeutics. 12 ${ }^{\text {th }}$ Ed. New York: Mc Graw Hill; 2011.

2. American Diabetes Association. Diagnosis and classification of diabetes mellitus. Diabetes Care 2010;33:S62-9.

3. Nyenwe E, Jerkins TW, Umpierrez GE, Kitabchi AE Management of type 2 diabetes: evolving strategies for the treatment of patients with type diabetes. Metabolism 2011;60:1-23.

4. Pickup J. Human insulin. Br Med J 1986;292:155-7.

5. Brown H, Sanger F, Kitai R. The structure of pig and sheep insulin. Biochem J 1955;60:556-5.

6. Smith LF. Amino acid sequences of insulins. Diabetes 1972;21:457-60.

7. De Leeuw I, Delvigne C, Bekaert J. Insulin allergy treated with human insulin (recombinant DNA). Diabetes Care 1982;5:168-70.

8. Ghazavi MK, Johnston GA. Insulin allergy. Clin Dermatol 2011;29:300-5.

9. American Diabetes Association. Classification and diagnosis of diabetes. Diabetes Care 2015;38:S8-16.

10. Yaturu S. Insulin therapies: current and future trends at dawn World J Diabetes 2013;4:1-7.

11. Novak B, Metelko Z. New trends in insulin therapy. Diabetol Croat 2003;32:55-63.

12. Katzung BG, Masters SB, Trevor AJ. Basic and clinical pharmacology. 12 $2^{\text {th }}$ Ed. New York: Tata McGraw-Hill; 2012.

13. Monami M, Marchionni N, Mannucci E. Long-acting insulin analogues vs NPH human insulin in type 1 diabetes, a metaanalysis. Diabetes Obes Metab 2009;11:372-8.

14. McGibbon A, Richardson C, Hernandez RNC, Dornan J. Pharmacotherapy in type 1 diabetes. Can J Diabetes 2013;37:S56-60.

15. Anonymous. DAFNE study group: training in flexible, intensive insulin management to enable dietary freedom in people with type 1 diabetes: dose adjustment for normal eating (DAFNE) randomised controlled trial. Br Med J 2002;325:1-6.

16. Anonymous. The diabetes control and complications trial research group. Adverse events and their association with treatment regimens in the diabetes control and complications trial. Diabetes Care 1995;18:1415-27.

17. Gruesser M, Hartmann $\mathrm{P}$, Schlottmann N, Joergens V Structured treatment and teaching programme for type 2 diabetic patients on conventional insulin treatment: evaluation of reimbursement policy. Patient Educ Couns 1996;29:123-30.

18. Anonymous. The diabetes control and complications tria research group: Design and methodologic considerations for the feasibility phase. Diabetes 1986;35:530-45. 
19. Anonymous. The diabetes control and complications trial research group. The effect of intensive treatment of diabetes on the development and progression of long-term complications in insulin-dependent diabetes mellitus. $\mathrm{N}$ Engl J Med 1993;329:977-86

20. Berghe GVD, Wouters P, Weekers F, Verwaest C, Bruyninckx F, Schetz M, et al. Intensive insulin therapy in critically ill patients. N Engl J Med 2001;345:1359-67.

21. Al-Fifi SH. Intensive insulin treatment versus conventional regimen for adolescents with type 1 diabetes, benefits and risks. Saudi Med J 2003;24:485-7.

22. Cao SG, Ren JA, Shen B, Chen D, Zhou YB, Li JS. Intensive versus conventional insulin therapy in type 2 diabetes patients undergoing D2 gastrectomy for gastric cancer: a randomized controlled trial. World J Surg 2011;35:85-92.

23. Azevedo JRAD, Lima ERM, Cossetti RJD, Azevedo RPDA Intensive insulin therapy versus conventional glycemic control in patients with acute neurological injury: a prospective controlled trial. Arq Neuro Psiquiatr 2007;65:733-8.

24. Rodger W. Insulin-dependent (type I) diabetes mellitus. Can Med Assoc J 1991;145:1227-37.

25. Kitabchi AE, Gosmanov AR. Safety of rapid-acting insulin analogs versus regular human insulin. Am J Med Sci 2012;344:136-41.

26. Joshi S, Joshi P. A review of insulin and insulin regimens in type 2 diabetes. S Afr Fam Pract 2009;51:97-102.

27. Noble SL, Johnston E, Walton B. Insulin lispro: a fast-acting insulin analo. Am Fam Physician 1998;57:279-86.

28. Tripathi KD. Essential of medical pharmacology. $7^{\text {th }}$ ed. New Delhi: Jaypee Brother Medical Publisher; 2013.

29. Rave K, Klein O, Frick AD, Becker RHA. Advantage of premealinjected insulin glulisine compared with regular human insulin in subjects with type 1 diabetes. Diabetes Care 2006;29:1812-7.

30. Ozaki N, Oiso Y. Immunologic tolerance to the insulin analogue glulisine. Diabetes Care 2010;33:e39.

31. Urakami T, Kuwabara R, Habu M, Okuno M, Suzuki J, Takahashi S. Efficacy and safety of switching to insulin glulisine from other rapid-acting insulin analogs in children with type 1 diabetes. J Diabetes Invest 2015;6:87-90.

32. Mannucci E, Monami M, Marchionni N. Short-acting insulin analogues vs. regular human insulin in type 2 diabetes: a metaanalysis. Diabetes Obes Metab 2009;11:53-9.

33. Deckert T. Intermediate-acting insulin preparations: NPH and Lente. Diabetes Care 1980;3:623-6.

34. Vajo Z, Fawcwtt J, Duckworth WC. Recombinant DNA technology in the treatment of diabetes: Insulin analogs. Endocr Rev 2001;22:706-17.

35. Kurtzhals P, Schaffer L, Sorensen A, Kristensen C, Jonassen I, Schmid $\mathrm{C}$, et al. Correlations of receptor binding and metabolic and mitogenic potencies of insulin analogs designed for clinical use. Diabetes 2000;49:999-1005.

36. Owens DR, Coates PA, Luzio SD, Tinbergen JP, Kurzhals R. Pharmacokinetics of ${ }^{125}$ I-labeled insulin glargine (HOE 901) in healthy men: comparison with NPH insulin and the influence of different subcutaneous injection sites. Diabetes Care 2000;23:813-9.

37. Lepore G, Dodesini AR, Nosari I, Trevisan R. Both continuous insulin infusion and multiple daily insulin injection regimen with glargine as basal insulin are equally better than traditional multiple daily insulin injection treatment. Diabetes Care 2003;26:1321-2

38. Jones DR. Insulin detemir: improving the predictability of glycemic control. Int J Obes 2004;28:S29-34.

39. Home P, Bartley P, Jones DR, Broutin HH, Heeg JE, Abrams P, et al. Insulin detemir offers improved glycemic control compared with NPH insulin in people with type 1 diabetes. Diabetes Care 2004;27:1081-7.

40. Kalra S, Farooqi MH, El-Houni AE. High-mix insulins. Indian J Endocrinol Metab 2015;19:686-90.

41. Turner HE, Matthews DR. The use of fixed-mixture insulin in clinical practice. Eur J Clin Pharmacol 2000;56:19-25.

42. Nathan DM. Finding new treatments for diabetes-how many, how fast, how good. N Engl J Med 2007;356:437-40.
43. Stein SA, Lamos EM, Davis SN. A review of the efficacy and safety of oral antidiabetic drugs. Expert Opin Drug Saf 2013;12:153-75.

44. Lamanna C, Monami M, Marchionni N, Mannucci E. Effect of metformin on cardiovascular events and mortality: a metaanalysis of randomized clinical trials. Diabetes Obes Metab 2011;13:221-8.

45. Pollak M. The insulin and insulin-like growth factor receptor family in neoplasia: an update. Nat Rev Cancer 2012;16:159-69.

46. Ramachandran A, Snehalatha C, Mary S, Mukesh B, Bhaskar AD, Vijay $\mathrm{V}$. The Indian diabetes prevention programme shows that lifestyle modification and metformin prevent type 2 diabetes in Asian Indian subjects with impaired glucose tolerance (IDPP1). Diabetologia 2006;49:289-97

47. American Diabetes Association. Summary of revisions to the 2011 clinical practice recommendations. Diabetes Care 2011;34:S3.

48. Foretz M, Guigas B, Bertrand L, Pollak M, Viollet B. Metformin: from mechanisms of action to therapies. Cell Metab 2014;20:953-66.

49. Ito $H$, Ishida $H$, Takeuchi $Y$, Antoku S, Abe M, Mifune M, et al. Long-term effect of metformin on blood glucose control in nonobese patients with type 2 diabetes mellitus. Nutr Metab 2010;7:1-9.

50. Hirst JA, Farmer AJ, Ali R, Roberts NW, Stevens RJ. Quantifying the effect of metformin treatment and dose on glycemic control. Diabetes Care 2012;35:446-54.

51. Viollet B, Guigas B, Sanz GN, Leclerc J, Foretz M, Andreelli F. Cellular and molecular mechanisms of metformin: an overview. Clin Sci 2012;122:253-70.

52. Hur KY, Lee MS. New mechanisms of metformin action focusing on mitochondria and the gut. I Diabetes Invest 2015;6:600-9.

53. Maida A, Lamont BJ, Cao X, Drucker DJ. Metformin regulates the incretin receptor axis via a pathway dependent on peroxisome proliferator-activated receptor- $\alpha$ in mice. Diabetologia 2011;54:339-49.

54. Hundal HS, Ramlal T, Reyes R, Leiter LA, Klip A. Cellular mechanism of metformin action involves glucose transporter translocation from an intracellular pool to the plasma membrane in L6 muscle cells. Endocrinology 1992;131:116573.

55. Martin Montalvo A, Mercken EM, Mitchell SJ, Palacios HH, Mote PL, Scheibye Knudsen M, et al. Metformin improves health span and lifespan in mice. Nat Commun 2013;4:1-9.

56. Anonymous. The diabetes prevention program research group Long-term safety, tolerability, and weight loss associated with metformin in the diabetes prevention program outcomes study. Diabetes Care 2012;35:731-7.

57. DeFronzo RA. Pharmacologic therapy for type 2 diabetes mellitus. Ann Intern Med 1999;131:281-303.

58. Gavin JR. Symposium on glyburide: summary and closing remarks. Am J Med 1990;89:51S-3S.

59. Bosenberg LH, Zyl DGV. The mechanism of action of oral antidiabetic drugs: a review of recent literature. JEMDSA 2008;13:80-8

60. Ibrahim R. Diabetes mellitus type 2: a review of oral treatment options. Int I Pharm Pharma Sci 2010;2:21-30.

61. Panten U, Schwanstecher M, Schwanstecher C. Sulfonylurea receptors and mechanism of sulfonylurea action. Exp Clin Endocr Diab 1996;104:1-9.

62. Aguilar Bryan L, Nichols CG, Wechsler SW, Clement JP, Boyd AE, Gonzalez G, et al. Cloning the $\beta$ cell high-affinity sulphonylurea receptor: a regulator of insulin secretion. Science 1995;268:423-6

63. Proks P, Reimann F, Green N, Gribble F, Ashcroft F Sulfonylurea stimulation of insulin secretion. Diabetes 2002;51:S368-76.

64. Jackson L, Robertson L. Sulphonylureas (specifically glibenclamide) and their correct dosage. S Afr Med J 1989;76:286-9.

65. Li Y, Hu Y, Ley SH, Rajpathak S, Hu FB. Sulfonylurea use and incident cardiovascular disease among patients with type 2 
diabetes: prospective cohort study among women. Diabetes Care 2014;37:3106-13.

66. Bosenberg LH, Zyl DGV. The mechanism of action of oral antidiabetic drugs: a review of recent literature. J Endocr Metab Diab S Afr 2008;13:80-8.

67. Gerich JE. Oral hypoglycemic agent. N Engl J Med 1989;321:1231-45.

68. Ambavane V, Patil R, Ainapure SS. Repaglinide, a short-acting insulin secretagogues for postprandial hyperglycaemia. Drug Rev 2002;48:246-8.

69. Rosenstock J, Hassman DR, Madder RD, Brazinsky SA, Farrell J, Khutoryansky $\mathrm{N}$, et al. Repaglinide versus nateglinide monotherapy. Diabetes Care 2004;27:1265-70.

70. Murad HAS, Hamza M, Hamza SA. Repaglinide as a safe alternative against hypoglycemia in fasting elderly diabetic patients: a single-blinded, placebo-controlled, six-period, crossover study. Afr J Pharm Pharmacol 2013;7:763-9.

71. Tsang MW. The management of type 2 diabetic patients with hypoglycaemic agents. ISRN Endocrinol 2012:1-9. https://doi.org/10.5402/2012/601380

72. Campbell I. Oral antidiabetic drugs: their properties and recommended use. Prescriber 2007;18:56-74.

73. Saltiel AR, Olefsky JM. Thiazolidinediones in the treatment of insulin resistance and type II diabetes. Diabetes 1996;45:1661-9.

74. Hauner $\mathrm{H}$. The mode of action of thiazolidinediones. Diabetes/Metab Res Rev 2002;18:S10-5.

75. Diaz Delfin J, Morales M, Caelle CH. Hypoglycemic action of thiazolidinediones/peroxisome proliferator-activated receptor $\gamma$ by inhibition of the c-Jun $\mathrm{NH}_{2}$-terminal kinase pathway. Diabetes 2007;56:1865-71.

76. Nesto RW, Bell D, Bonow RO, Fonseca V, Grundy SM, Horton ES, et al. Thiazolidinedione use, fluid retention, and congestive heart failure. Diabetes Care 2004;27:256-63

77. Flanagan PR, Forstner GG. Purification of rat intestinal maltase/glucoamylase and its anomalous dissociation either by heat or by low pH. Biochem J 1978;173:553-6.

78. Derosa G, Maffioli P. $\alpha$-Glucosidase inhibitors and their use in clinical practice. Arch Med Sci 2012;9:899-906.

79. Van de Laar FA. Alpha-glucosidase inhibitors in the early treatment of type 2 diabetes. Vasc Health Risk Manage 2008:4:1189-95.

80. Van de Laar FA, Lucassen PL, Akkermans RP, Van de Lisdonk $\mathrm{EH}$, Rutten GE, Weel CV. $\alpha$-glucosidase inhibitors for patients with type 2 diabetes. Diabetes Care 2005;28:154-63.

81. Scheen AJ. Clinical efficacy of acarbose in diabetes mellitus: a critical review of controlled trials. Diabetes Metab 1998:24:311-20

82. Kao CC, Wu PC, Wu CH, Chen LK, Chen HH, Wu MS, et al. Risk of liver injury after $\alpha$-glucosidase inhibitor therapy in advanced chronic kidney disease patients. Sci Rep 2016;6:1-6.

83. Seino Y, Fukushima M, Yabe D. GIP and GLP-1, the two incretin hormones: similarities and differences. J Diabetes Invest 2010;1:8-23.

84. Holst JJ, Gromada J. Role of incretin hormones in the regulation of insulin secretion in diabetic and nondiabetic humans. Am J Physiol 2004;287:E199-206.

85. Schweizer A, Foley JE, Kothny W, Ahren B. Clinical evidence and mechanistic basis for vildagliptin's effect in combination with insulin. Vasc Health Risk Manage 2013;9:57-64

86. Wheeler MB, Gelling RW, McIntosh $\mathrm{CH}$, Georgiou J, Brown JC Pederson RA. Functional expression of the rat pancreatic islet glucose-dependent insulinotropic polypeptide receptor: ligand binding and intracellular signaling properties. Endocrinology 1995;36:4629-39.

87. Hinnen D, Nielsen LL, Waninger A, Kushner P. Incretin mimetics and DPP-IV inhibitors: new paradigms for the treatment of type 2 diabetes. I Am Board Fam Med 2006;19:612-20

88. Kieffer TJ, McIntosh CH, Pederson RA. Degradation of glucosedependent insulinotropic polypeptide and truncated glucagonlike peptide 1 in vitro and in vivo by dipeptidyl peptidase IV. Endocrinology 1995;136:3585-96.

89. Yavropoulou MP, Pikilidou M, Kotsa K, Michopoulos A Papakonstantinou E, Yovos JG. Efficacy and tolerability of vildagliptin as first line treatment in patients with diabetes type 2 in an outpatient setting. J Diabetes Metab Disord 2015;14:1-7.

90. Kutoh E. Sitagliptin is effective and safe as an add-on to insulin in patients with absolute insulin deficiency: a case series. J Med Case Rep 2011;5:1-5

91. Charbonnel B, Karasik A, Liu J, Wu M, Meininger G. Efficacy and safety of the dipeptidyl peptidase- 4 inhibitor sitagliptin added to ongoing metformin therapy in patients with type 2 diabetes inadequately controlled with metformin alone. Diabetes Care 2006;29:2638-43

92. Aschner P, Kipnes MS, Lunceford JK, Sanchez M, Mickel C, Williams Herman DE. Effect of the dipeptidyl peptidase-4 inhibitor sitagliptin as monotherapy on glycemic control in patients with type 2 diabetes. Diabetes Care 2006;29:2632-7.

93. Ahren B, Landin Olsson M, Jansson PA, Svenson M, Holmes D, Schweizer A. Inhibition of dipeptidyl peptidase-4 reduces glycemia, sustains insulin levels and reduces glucagon levels in type 2 diabetes. J Clin Endocrinol Metab 2004;89:2078-84.

94. Ahren B, Schweizer A, Dejager S, Villhauer EB, Dunning BE, Foley JE. Mechanisms of action of the dipeptidyl peptidase-4 inhibitor vildagliptin in humans. Diabetes Obes Metab 2011;13:775-83

95. El-Ouaghlidi A, Rehring E, Holst JJ, Schweizer A, Foley J, Holmes $\mathrm{D}$, et al. The dipeptidyl peptidase 4 inhibitor vildagliptin does not accentuate glibenclamide-induced hypoglycemia but reduces glucose-induced glucagon-like peptide 1 and gastric inhibitory polypeptide secretion. J Clin Endocrinol Metab 2007;92:4165-71.

96. Yavropoulou MP, Pikilidou M, Kotsa K, Michopoulos A Papakonstantinou E, Yovos JG. Efficacy and tolerability of vildagliptin as first-line treatment in patients with diabetes type 2 in an outpatient setting. I Diabetes Metab Disord 2015;14:1-7.

97. Jeon $\mathrm{JH}, \mathrm{Oh}$ TK. Comparison of vildagliptin-metformin and glimepiride-metformin treatments in type 2 diabetic patients. Diabetes Metab J 2011;35:529-35.

98. Neumiller JJ, Campbell RK. Saxagliptin: a dipeptidyl peptidase-4 inhibitor for the treatment of type 2 diabetes mellitus. Am J Health Syst Pharm 2010;67:1515-25.

99. Dave DJ. Saxagliptin: a dipeptidyl peptidase-4 inhibitor in the treatment of type 2 diabetes mellitus. J Pharmacol Pharmacother 2011;2:230-5

100. Hollander PA, Kushner P. Type 2 diabetes comorbidities and treatment challenges: rationale for DPP-4 inhibitors. Postgrad Med 2010;122:71-80.

101. Anonymous. Saxagliptin (Onglyza) for type 2 diabetes. Med Lett Drugs Ther 2009;51:85-6.

102. DeFronzo RA, Hissa MN, Garber AJ, Gross JL, Duan RY Ravichandran $\mathrm{S}$, et al. The efficacy and safety of saxagliptin when added to metformin therapy in patients with inadequately controlled type 2 diabetes with metformin alone. Diabetes Care 2009;32:1649-55.

103. Li CJ, Liu XJ, Bai L, Yu Q, Zhang QM, Yu P, et al. Efficacy and safety of vildagliptin, saxagliptin or sitagliptin as add-on therapy in Chinese patients with type 2 diabetes inadequately controlled with dual combination of traditional oral hypoglycemic agents. Diabetol Metab Syndr 2014;6:1-9.

104. Ott C, Raff U, Schmidt S, Kistner I, Friedrich S, Bramlage P, et al. Effects of saxagliptin on early microvascular changes in patients with type 2 diabetes. Cardiovasc Diabetol 2014;13:1-9.

105. Peters JU. 11 y of cyanopyrrolidines as DPP-IV inhibitors. Curr Top Med Chem 2007; 7:579-95.

106. Deacon CF, Holst JJ. Linagliptin. A xanthine-based dipeptidy peptidase-4 inhibitor with an unusual profile for the treatment of type 2 diabetes. Expert Opin Invest Drugs 2010;19:133-40.

107. Guedes EP, Hohl A, Melo TG, Lauand F. Linagliptin: farmacology, efficacy and safety in type 2 diabetes treatment. Diabetol Metab Syndr 2013;5:1-7.

108. Gallwitz B. Safety and efficacy of linagliptin in type 2 diabetes patients with common renal and cardiovascular risk factors. Ther Adv Endocrinol Metab 2013;4:95-105.

109. Kern M, Kloting N, Heiko G, Niessen HG, Thomas L, Stiller D, et al. Linagliptin improves insulin sensitivity and hepatic steatosis in diet-induced obesity. PLoS One 2012;7:1-10 
110. Baetta R, Corsini A. Pharmacology of dipeptidyl peptidase-4 inhibitors: similarities and differences. Drugs 2011;71:1441-67.

111. DeFronzo RA, Fleck PR, Wilson CA, Mekki Q. Efficacy and safety of the dipeptidyl peptidase-4 inhibitor alogliptin in patients with type 2 diabetes and inadequate glycemic control. Diabetes Care 2008;31:2315-7

112. Raalte DHV, Genugten REV, Eliasson B, Goede DLM, Mari A, Tura A, et al. The effect of alogliptin and pioglitazone combination therapy on various aspects of $\beta$-cell function in patients with recent-onset type 2 diabetes. Eur J Endocrinol 2014;170:565-74.

113. Mashitani T, Noguchi R, Okura Y, Namisaki T, Mitoro A, Ishii H. Efficacy of alogliptin in preventing non-alcoholic fatty liver disease progression in patients with type 2 diabetes. Biomed Rep 2016;4:183-7.

114. Ndefo UA, Okoli O, Erowele G. Alogliptin: a new dipeptidyl peptidase- 4 inhibitor for the management of type 2 diabetes mellitus. Am J Health Syst Pharm 2014;71:103-9.

115. Hood R, Valentine V, Mac S, Polonsky WH. Use of exenatide in patients with type 2 diabetes. Diabetes Spectr 2006;19:181-6.

116. Nielsen LL, Young AA, Parkes D. Pharmacology of exenatide (synthetic exendin-4): a potential therapeutic for improved glycemic control of type 2 diabetes. Regul Pept 2004;117:77-88.

117. DeFronzo RA, Ratner RE, Han J, Kim DD, Fineman MS, Baron AD. Effects of Exenatide (exendin-4) on glycemic control and weight over $30 \mathrm{w}$ in metformin-treated patients with type 2 diabetes. Diabetes Care 2005;28:1092-100.

118. Davies MJ, Bergenstal R, Bode B, Kushner RF, Lewin A, Skoth TV, et al. Efficacy of Liraglutide for weight loss. Among patients with type 2 diabetes: the scale diabetes randomized clinical trial. JAMA 2015;314:687-99.

119. Zinman B, Gerich J, Buse JB, Lewin A, Schwartz S, Raskin P, et al Efficacy and safety of the human glucagon-like peptide-1 analog liraglutide in combination with metformin and thiazolidinedione in patients with type 2 diabetes (LEAD-4 Met+TZD). Diabetes Care 2009;32:1224-30.

120. Garber A, Henry R, Ratner R, Garcia Hemandez PA, Rodriguez Pattzi $\mathrm{H}$, Olvera-Alvarez I, et al. Liraglutide versus glimepiride monotherapy for type 2 diabetes (LEAD-3 Mono): a randomised, 52-week, phase III, double-blind, paralleltreatment trial. Lancet 2008;373:473-81.

121. Clements JN, Shealy KM. Liraglutide, an injectable option for the management of obesity. Ann Pharmacother 2015;49:93844.

122. Kuhadiya N, Malik R, Bellini N, Patterson J, Traina A, Makdissi A et al. Liraglutide as additional treatment to insulin in obese patients with type 1 diabetes mellitus. Endocr Pract 2013;19:963-7.

123. Blair HA, Keating GM. Albiglutide: a review of its use in patients with type 2 diabetes mellitus. Drugs 2015;75:651-63.

124. Rendell MS. Albiglutide for the management of type 2 diabetes. Expert Rev Endocrinol Metab 2018;13:1-8.

125. Burness CB, Scott LJ. Dulaglutide: a review in type 2 diabetes. Bio Drugs 2015;29:407-18.

126. Wasir JS, Mithal A, Agarwal P, Mittal A. Once-weekly dulaglutide therapy in type 2 diabetic subjects, real-world evidence from a tertiary care diabetes center in India. Indian Endocr Metab 2018;22:728-34.

127. Gomez Peralta F, Abreu C. Profile of semaglutide in the management of type 2 diabetes: design, development, and place in therapy. Drug Des Dev Ther 2019;13:731-8.

128. Rosenstock J, Balas B, Charbonnel B, Bolli GB, Boldrin M, Ratner $\mathrm{R}$, et al. The fate of taspoglutide, a weekly GLP-1 receptor agonist, versus twice-daily exenatide for type 2 diabetes: the Temerge 2 trial. Diabetes Care 2013;36:498-504.

129. Danial E Baker, DE Levien TL. Lixisenatide. Hosp Pharm 2017;52:65-80.

130. Werner U, Haschke G, Herling AW, Kramer W. Pharmacological profile of lixisenatide: a new GLP-1 receptor agonist for the treatment of type 2 diabetes. Regul Pept 2010;164:58-64

131. Okere AN, Montesdeoca J, Glasper A, Diaby V. An evaluation of the clinical therapeutic effect of Lixisenatide in type 2 diabetes patients: a systematic literature review. Curr Diabetes Rev 2018;14:363-75.
132. Kalra S. Sodium-glucose co-transporter-2 (sglt2) inhibitors: a review of their basic and clinical pharmacology. Diabetes Ther 2014;5:355-66.

133. Nauck MA. Update on developments with SGLT2 inhibitors in the management of type 2 diabetes. Drug Des Dev Ther 2014;8:1335-80

134. Nakajima H, Okada S, Mohri T, Kanda E, Inaba N4, Hirasawa Y, et al. Dapaglifozin improves treatment satisfaction in overweight patients with type 2 diabetes mellitus: a patientreported outcome study (PRO study). Diabetol Metab Syndr 2018;10:1-11

135. Anderson SL. Dapagliflozin efficacy and safety: a perspective review. Ther Adv Drug Saf 2014;5:242-54.

136. Jakher H, Chang TI, Tan M, Mahaffey KW. Canagliflozin reviewsafety and efficacy profile in patients with T2DM. Diabetes, Metab Syndr Obes: Targets Ther 2019;12:209-15.

137. Henry RR, Thakkar P, Tong C, Polidori D, Alba M. Efficacy and safety of canagliflozin, a sodium-glucose cotransporter 2 inhibitor, as add-on to insulin in patients with type 1 diabetes. Diabetes Care 2015;38:2258-65.

138. Sharma V, Sharma S, Jaiswal S, Ghanghas RR, Boddepalli D, Sharma AK. Ertugliflozin: a novel anti-diabetic drug. Int J Basic Clin Pharmacol 2018;7:1-4.

139. Hu J, Deng A, Zhao Y. Ertugliflozin as a monotherapy for the treatment of type 2 diabetes. Expert Opin Pharmacother 2018;19:1841-7.

140. Neumiller JJ. Empagliflozin: a new sodium-glucose cotransporter 2 (SGLT2) inhibitor for the treatment of type 2 diabetes. Drugs Context 2014;3:3-18.

141. Zinman B, Wanner C, Lachin JM, Fitchett D, Bluhmki E, Hantel S, et al. Empagliflozin, cardiovascular outcomes, and mortality in type 2 diabetes. N Engl J Med 2015;373:2117-28.

142. Hay DL, Chen S, Lutz TA, Parkes DG, Roth JD. Amylin pharmacology, physiology and clinical potential. Pharmacol Rev 2015;67:564-600.

143. Ryan G, Briscoe TA, Jobe L. Review of pramlintide as adjunctive therapy in treatment of type 1 and type 2 diabetes. Drug Des Dev Ther 2008;2:203-14.

144. Younk LM, Mikeladze M, Davis SN. Pramlintide and the treatment of diabetes: a review of the data since its introduction. Expert Opin Pharmacother 2011;12:1439-51.

145. DeFronzo RA. Bromocriptine: a sympatholytic, D2-dopamine agonist for the treatment of type 2 diabetes. Diabetes Care 2011;34:789-94

146. Shivaprasad C, Kalra S. Bromocriptine in type 2 diabetes mellitus. Indian J Endocrinol Metab 2011;15:S17-24.

147. Kandasamy K, Rajagopal SS, Ramalingam KK, Krishnan K. Prevalence of diagnosed and undiagnosed diabetes in a rura community: a home-based screening. Asian J Pharm Clin Res 2018;11:454-7.

148. Kumar M, Shivgotra VK, Nanda H. Gender-wise prevalence of diabetes among the Indian population: a meta-analysis using $\mathrm{R}$ software. J Crit Rev 2020;7:683-91.

149. Mokdad AH, Ford ES, Bowman BA, Dietz WH, Vinicor F, Bales VS, et al. Prevalence of obesity, diabetes, and obesity-related health risk factors 2001. JAMA 2003;289:76-9.

150. Jain R, Jain P, Jain P. A review on treatment and prevention of diabetes mellitus. Int J Curr Pharm Res 2016;8:16-8.

151. Poornima KN, Kanimozhi S, Karthick N, Saravanan A, Padmavathi R. Skeletal muscle: one of the silent targets of diabetic complications. Asian J Pharm Clin Res 2018;9:206-8.

152. Fowle MJ. Diabetes treatment, part 1: diet and exercise. Clin Diabetes 2007;25:105-9.

153. Rabasa Lhoret R, Garon J, Langelier H, Poisson D, Chiasson JL. Effects of the meal carbohydrate content on insulin requirements in type 1 diabetic patients treated intensively with the basal-bolus (ultra lente-regular) insulin regimen. Diabetes Care 1999;22:667-73.

154. Franz MJ, Bantle JP, Beebe CA, Brunzell JD, Chiasson JL, Garg A et al. Nutrition principles and recommendations in diabetes. Diabetes Care 2004;27:S36-46.

155. Gannon MC, Nuttall JA, Damberg G, Gupta V, Nuttall FQ. Effect of protein ingestion on the glucose appearance rate in people with type 2 diabetes. J Clin Endocrinol Metab 2001;86:1040-7. 
156. Klein S, Sheard NF, Pi-Sunyer X, Daly A, Wylie Rosett J, Kulkarni $\mathrm{K}$, et al. Weight management through lifestyle modification for the prevention and management of type 2 diabetes: rationale and strategies: a statement of the American diabetes association, the North American association for the study of obesity, and the American Society for clinical nutrition. Diabetes Care 2004;27:2067-73.

157. Boule NG, Haddad E, Kenny GP, Wells GA, Sigal RJ. Effects of exercise on glycemic control and body mass in type 2 diabetes mellitus: a meta-analysis of controlled clinical trials. JAMA 2001;286:1218-27.
158. Sigal RJ, Kenny GP, Wasserman DH, Castaneda Sceppa C, White RD. Physical activity/exercise and type 2 diabetes. Diabetes Care 2006;29:1433-8.

159. Marwick TH, Hordern MD, Miller T, Chyun DA, Bertoni AG, Blumenthal RS, et al. Exercise training for type 2 diabetes mellitus impact on the cardiovascular risk a scientific statement from the American heart association. Circulation 2009; 119:3244-62.

160. Presetiawati IIN, Andrajati R, Sauriasari R. Effectiveness of a medication booklet and counseling on treatment adherence in type 2 diabetes mellitus patients. Int J Appl Pharm 2017;9:27-31. 